\title{
Enhancing the Glopan Food Systems Framework by Integrating Gender: Relevance for Women in African Agriculture
}

\author{
Elizabeth Mkandawire ${ }^{1, *(\mathbb{D}}$, Melody Mentz-Coetzee ${ }^{1}$, Margaret Najjingo Mangheni ${ }^{2}$ (D) and Eleonora Barusi ${ }^{3}$ \\ 1 Center for the Advancement of Scholarship, University of Pretoria, Pretoria 0002, South Africa; \\ melody.mentz-coetzee@up.ac.za \\ 2 Department of Extension and Innovation Studies, Makerere University, Kampala P.O. Box 7062, Uganda; \\ mnmangheni@agric.mak.ac.ug \\ 3 Faculty of Life Sciences, Humboldt-Universität zu Berlin, 10117 Berlin, Germany; eleonora.barusi@ugent.be \\ * Correspondence: elizabeth.mkandawire@up.ac.za
}

Citation: Mkandawire, E.;

Mentz-Coetzee, M.; Mangheni, M.N.; Barusi, E. Enhancing the Glopan Food Systems Framework by Integrating Gender: Relevance for Women in African Agriculture. Sustainability 2021, 13, 8564. https://doi.org/ $10.3390 /$ su13158564

Academic Editors: Frans Swanepoel, Stefano Marras, Simeon Ehui, Lise Korsten and Manfred Max Bergman

Received: 27 May 2021

Accepted: 23 July 2021

Published: 31 July 2021

Publisher's Note: MDPI stays neutral with regard to jurisdictional claims in published maps and institutional affiliations.

Copyright: (c) 2021 by the authors. Licensee MDPI, Basel, Switzerland. This article is an open access article distributed under the terms and conditions of the Creative Commons Attribution (CC BY) license (https:/ / creativecommons.org/licenses/by/ $4.0 /)$.

\begin{abstract}
Globally, gender inequalities constrain food security, with women often disproportionately affected. Women play a fundamental role in household food and nutrition security. The multiple roles women play in various areas of the food system are not always recognised. This oversight emerges from an overemphasis on one aspect of the food system, without considering how this area might affect or be affected by another aspect. This study aimed to draw on international commitments and treaties using content analysis to enhance the Global Panel on Agriculture and Food Security food systems framework by integrating a gender perspective. The study found that generally, there is a consensus on specific actions that can be taken to advance gender equality at specific stages of the food system. However, governance and social systems constraints that are not necessarily part of the food system, but have a significant bearing on men and women's capacity to effectively participate in the food system, need to be addressed. While the proposed conceptual framework has some limitations, it offers a foundation on which researchers, policymakers and other stakeholders can begin conceptualising the interconnectedness of gender barriers in the food system.
\end{abstract}

Keywords: gender; food systems; policy; agency; women; Africa

\section{Introduction}

Food insecurity is increasing globally, with almost $9 \%$ of the global population reported as food insecure [1]. Africa has the highest undernourished population of all regions, more than double the global average at 19\% [1]. The continent is significantly off-track to meet international and continental targets on ending hunger. Only one country (Uganda) is on track to reducing stunting in children under five to $10 \%$ by 2025 [2]. Women disproportionately experience moderate or severe food insecurity compared to men, with implications for children's and household nutrition [1]. While women are considered essential to ensuring food and nutrition security, they remain significantly marginalised in the broader food system [3]. Bezner Kerr et al. (2019) [4] and Lemke (2003) [5] suggest that interventions that are accompanied by a focus on changing gender relations and redistributing labour more equitably have been more successful in improving household food security.

The multiple roles women play in various areas of the food system are not always recognised [6]. This oversight emerges from an overemphasis on one area of the food system, without considering how this area might affect or be affected by another segment [7]. For example, women are often considered critical players in household food and nutrition security. However, women's productivity and participation in economic activities are often constrained by limited access to and control over inputs, training, technologies and other services [8]. Consequently, they retain limited control over household resources and decision-making power to acquire nutritious food [9]. Gender roles, norms and relations 
intersect with segments of the food system and often further marginalise women in the food system. Gender refers to men and women's socially allocated roles and responsibilities and the relationships between men and women [10]. The dynamic gender systems that define socially and culturally accepted norms underpinning men and women's relations, identities, behaviour and entitlements manifest in various spheres of agriculture and food systems globally. Often, gender relations comprise complex inter-dependent roles, responsibilities in agricultural production and food provisioning. Women and men are not autonomous agents but rely on each other and negotiate in different ways to ensure that household needs are met [11,12].

Generally, where gender is concerned, there is a tendency to focus only on women as a development target or category of analysis and to neglect the gender roles, responsibilities and relations that shape women's participation in the food system and empowerment [7]. Focus on women alone overlooks the systemic inequalities that constrain women's participation in the food system. This paper applies gender relations theory in the context of gender in agriculture.

Women's empowerment is considered a pathway to achieving improved maternal and child nutrition outcomes and alleviating poverty; however, efforts to empower women cannot be viewed in isolation of other gender roles women play in the food system. These roles may be in direct conflict with their role in household nutrition [7]. For example, increasing women's involvement in economic activities may reduce the time they can spare to prepare nutritious food. Consequently, convenient foods such as polony (a ground pork sausage containing cubes of pork fat), fried chips and white bread, which are often high in energy and low in nutrients, may be the most practical alternative [9]. Challenges related to food production, processing, storage, transportation, trade, transformation and retailing, and how these activities deliver on improved diets need to be investigated from a gender perspective [13]. The interconnectedness of these challenges also needs to be understood. Patel et al. (2015) [14], Bezner Kerr et al. [4] and Caron [15] point to the importance of systems approaches for achieving gender, food security and nutrition.

Analysing gender from a food systems perspective is critical to our understanding of the conflicting roles and expectations placed on women. Doss [16] argues how evidence suggesting that providing women access to the same inputs as men could increase agricultural yields by up to $30 \%$ has perpetuated the notion that women can and should be responsible for food security. Women already face increased pressure to meet their domestic, productive and community responsibilities. Applying a gender lens to the food system can assist in avoiding the trap of placing undue expectations on women to "fix" the food system. It also aids in understanding the positive and negative unintended consequences of effecting change in one aspect of the food system and what it means for other aspects. For example, Garcia and Wanner [17] explain that in a project aiming to promote women's participation in dairy production, girls began dropping out of school to contribute to labour. This example illustrates how promoting women's empowerment in agricultural production can undermine other desired outcomes, such as girl's education and ultimately women's future employment and income-generating opportunities.

We conducted a narrative review to assist us in identifying articles related to gender and the food system. Articles from Web of Science databases, JSTOR, Agricultural and Environment Science Collection, Agricultural Science Collection and Agricola were sampled to identify existing literature. We sampled several agriculture databases because of our interest in gender and all stages of agricultural production and consumption. We included Web of Science and JSTOR to increase the robustness of our review. These articles were then refined by region to focus on the African context. We found that a significant amount of literature exists on gender and agriculture, gender and diets and gender and climate change. Some studies have been conducted on gender and trade and markets, gender and consumer demand, gender and consumer purchasing power and gender and value chains. Some studies cut across several of these components. This study aims to augment the existing literature by offering a lens for integrating gender in the African food system. Such 
a framework would provide policymakers with a tool to unpack the trade-offs women make in order to participate in certain agricultural-related or other activities. It would also ease the identification of leverage points that exist at certain intersections of food systems components. Den Boer et al. [18] argue that it is at these leverage points where interventions would be most effective.

International agreements, conventions and commitments offer countries guidance on development priorities and their integration into policy. While these documents do not refer specifically to food systems per se, guidance is provided on how gender can be advanced in the main components that comprise it: agricultural production, trade and marketing, consumer purchasing power, food transformation and consumer demand and food environment.

This paper aims to enhance the Global Panel on Agriculture and Food Security (Glopan) food systems framework by using international agreements and conventions related to food security and nutrition to identify policy actions for integrating gender into the components of the Glopan food systems framework. African food systems stakeholders involved in the development of food policies are the primary target audience. They could use the enhanced framework presented in this paper to inform how they integrate gender in food systems policies. Providing a gender lens to the African food system will ensure that integrating gender remains a priority of global debates concerning food systems, particularly as the Global Food Systems summit approaches.

We used commitments and agreements related to food security because this agenda has driven issues related to food systems on the African continent. These are the frameworks with which the policymakers, donors and other stakeholders in this arena are familiar. Using these documents allows us to begin unpacking food security into the food systems components while also enabling stakeholders to understand these agreements within the context of food systems.

In the next section, we explain the significance of using a food systems approach and why we use the Glopan food systems framework as the basis for integrating gender in the food system.

\subsection{Food Systems}

Experts realise that focusing on agricultural productivity alone is not an efficient approach to ending hunger and malnutrition [6]. While agriculture has immense potential to reduce malnutrition in its various forms, its intersections with other sectors are essential to maximising the impact on nutrition [19]. In fact, in low-income countries, studies suggest that agricultural policy and practice have led to limited changes in nutrition. Some of the contributing factors to the limited impact include lack of adequate sanitation and hygiene facilities and lack of women's empowerment [20].

A systems approach is needed to ensure that households can afford healthy diets in a manner that is environmentally sustainable [13]. The concept of food systems is not new; however, it has regained interest because of emerging concerns around environmental sustainability, diet and health issues. Generally, consensus exists that the main objective of a food system is to deliver food and nutrition security sustainably both in terms of equity, welfare and environmental preservation [21].

In 2014, the Glopan produced a technical brief on how agriculture and food systems policy can improve nutrition [13]. This brief aimed to consolidate different areas of policy interventions to facilitate a sustainable environment for food systems that can deliver quality diets. Figure 1 is a user-friendly framework that was developed to illustrate the different components of the food system and the possible policy actions that could be pursued at each stage. Using this framework as a lens, in this study, we aimed to understand how international conventions, commitments and agreements related to food security can provide a lens for integrating gender equality in the food system. Figure 1 below offers an illustrated summary of the components of a food system. 


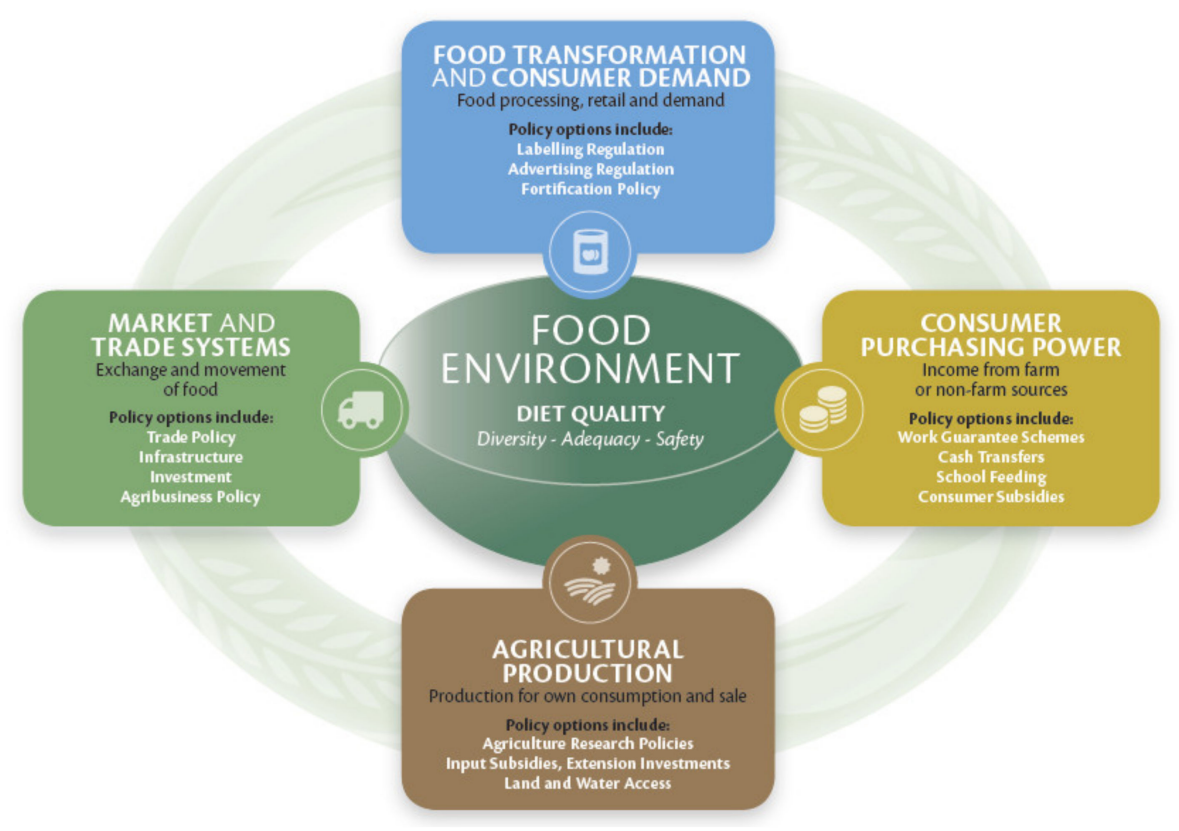

Figure 1. Glopan summarised food systems framework (Source: Glopan, 2014 [13]).

While other food systems frameworks exist, the Glopan framework was informed by global experts in food and nutrition security. Though the same might be said of the 2017 HLPE food systems framework [9], the simplicity with which the food systems components are captured in the Glopan framework eases an assessment of how gender perspectives can be integrated into the food system. This framework also eases the understanding of policymakers who might not be technical experts in food systems or gender. The authors used this framework as a foundation for consolidating and identifying possible policy actions that can facilitate the integration of gender into the food system.

\subsection{Gender and the Food System}

Formal and informal institutions govern food systems. Formal institutions include governance structures, policies and legislation that inform the food system. Informal systems include social systems that influence the functioning of the food system. Gender is an informal system that defines men and women's participation in the food system [20]. In this section, we unpack some of the gender literature associated with each of the food systems components of the Glopan framework.

\subsubsection{Agricultural Production}

Societal norms inform the gender roles women and men play in agricultural production. In many African countries, women play a significant role in subsistence farming; however, men and women's role in agricultural production is not homogenous and varies depending on context. For example, in Northern Ghana, contrary to the norm elsewhere in Sub Saharan Africa, men are responsible for meeting the staple food needs of the household, while women are responsible for generating cash for other food products [11]. Regardless of the context, there is a consensus that women across the continent typically lack access to agricultural inputs, technologies and services, constraining their productivity [16]. Evidence from Ghana, Kenya, Tanzania and Zambia indicates that most of the agricultural labour force are women, yet significant barriers constrain their productivity [11,22-25]. Women's limited access to quality land, improved seed varieties, fertiliser, extension services and technologies are barriers that increase the gender yield gap.

Women's low productivity is compounded by their limited decision-making and control over agricultural inputs and outputs [20]. Addressing issues of access and control simultaneously is critical to the unlocking of women's agricultural production potential. 
For example, while access to secure land tenure is considered a significant hindrance to women's productivity, increasing women's access to land without considering gender dynamics within the household will not increase women's productivity. Several studies found that women's secure access to land did not translate to increased agricultural productivity because of women's limited participation in household decision-making. Behrman et al. (2012) estimate that if women had equal decision-making power concerning food in the home, malnutrition could decrease by $13 \%$.

In particular, women's limited control over land and land rights prevents significant challenges towards food security, nutrition, gender equality and women's health and wellbeing [26]. Large scale land transfers that have siezed men and women of land rights have increased the work burden on women. While households are sometimes compensated for the transfer of land, women rarely control the income from these transactions as men traditionally make decisions related to household income [27]. Men and women can no longer produce sufficient food for their families, resulting in men migrating to urban areas to seek employment. Women are increasingly taking up men's agricultural responsibilities in addition to housework and care responsibilities. In addition to women's multiple responsibilities, women also take up seasonal employment to meet household needs [28].

\subsubsection{Consumer Purchasing Power}

Multiple studies indicate that African women invest more of their income on household food, nutrition and well-being than men [20,29,30]. Women, however, often earn less than men, limiting their consumer purchasing power. Women's lower income is explained by social gender norms that restrict their income-generating opportunities. For example, in South Africa, fewer women are involved in the labour market where formal structures, including legal contracts, offer them job security and stable income. Consequently, more women than men remain unemployed. More women are involved in the informal sector [29]. de Groot et al. [31] argue that women typically dominate the informal economy because it offers them more flexibility given their multiple responsibilities. Women carry multiple socially determined responsibilities in the home, including child care and housework [32]. Disparities in women's time use, compared to men, have compromised women's productivity and income-generating opportunities. Few households in rural African communities have access to electricity and running water, constraining women who spend much of their time collecting firewood and water. These activities limit the time women could spend on agricultural, education or income-generating activities [32].

\subsubsection{Market and Trade Systems}

Women face time constraints in participating in market and trade systems. Men are more likely to be involved in formal markets and women in informal markets [29]. Gender determines the types of commodities men and women typically sell. These commodities determine the types of markets men and women can access. For example, studies in Tanzania indicate that women typically sell vegetables directly to consumers, whereas men sell grains. Even in cases where men and women sell the same commodities, women often sell locally while men trade regionally or internationally [23,33]. Although both men and women are active in agriculture, women face limited market opportunities compared to their male counterparts. These opportunities are constrained by time (as discussed above), access to transportation and cultural restrictions that limit women's mobility or entry into certain spaces [20]. Both men and women's access to markets has a positive impact on household nutrition. However, women's access to markets has almost double the impact of men's [30].

\subsubsection{Food Transformation and Consumer Demand}

Many external factors influence the types of products consumers typically demand, including process, availability, convenience and desires [20]. Women typically determine the kinds of food to purchase as they are responsible for food preparation. The types of 
food products men and women demand are often influenced by the various activities in which they are involved. For example, in Kenya, both men and women are involved in the sale of bananas. However, the types of cultivars they purchase/demand are informed by their use. Women trade bananas locally, and as such, the types of bananas they demand are determined by consumers' purchases. Men, on the other hand, use bananas for brewing beer to sell. Their cultivar demands are influenced by taste [34]. Women are often the intended beneficiaries of nutrition education programmes. As such, women are often more willing to pay for value addition than men. For example, a study from Kenya indicates that women are more willing to pay higher prices for frozen cowpea leaves because they understand the nutritional benefits and the necessity for improved storage $[20,24]$.

\subsubsection{Food Environment}

Much of the literature on gender and diets indicates that women are responsible for preparing food. However, they do not have complete decision-making over all the choices involved in food preparation [20]. For example, food purchases might be made by men in the household, limiting women's choice of what food to prepare. Food preparation, in particular, increases women's time poverty because of constraints faced in accessing water and fuel, again limiting the amount of time they have to pursue other activities necessary for their empowerment [17]. Women may have to make trade-offs between income-generating activities and food preparation. They often compromise their nutrition in order to participate in income-generating activities [20,35].

Global discourse, informed by literature such as the Lancet Series on maternal and child under-nutrition, and international commitments such as the World Health Assembly, emphasise nutrition [36,37]. Attention to women and children's nutrition during the first thousand days of a child's life-from conception until age two-is prioritised [30]. Consequently, much of the literature on diets in Africa is centred around improving maternal and child nutrition [38-42]. An overemphasis on women has undermined men's nutrition, overlooking important gender dynamics related to hegemonic masculinity and the significant implications of these on household food and nutrition security. Some examples of the impact of hegemonic masculinities on food security include men's use of household resources for alcohol consumption [43-46] and polygamy. In relation to polygamy, the distribution of limited food resources by men amongst co-wives and children have important implications on household food and nutrition security [47,48]. An overemphasis on women also reinforces gender norms and the notion that women should be solely responsible for food and nutrition [49].

Many of the gender-based constraints described in the literature arise from socially constructed gender roles and hierarchical power relations that undermine men and women's participation in the food system. Efforts to improve women's participation in, and the benefits they accrue from, the food system must unpack the trade-offs women make, the unintended consequences of interventions. These efforts must also include avoiding placing undue pressure on women to improve food and nutrition security. Such efforts can only be informed by a holistic approach to understanding how gender intersects with the food system.

\section{Materials and Methods}

The authors used content analysis to conduct an in-depth review of 18 food and nutrition security commitments, conventions and agreements. A latent analysis was applied $[50,51]$ to describe what was said about the different components of the food system and the gender-related topics and to make inferences between the two themes across the different documents. Latent analysis is a systematic and objective method used to analyse verbal, visual or written data to make replicable or valid inferences by providing descriptive results. Using this approach enabled us to identify sub-themes related to each of the main categories (food systems components) of the Glopan framework and to identify subthemes. These subthemes are policy options for integrating gender into food systems 
components. Two researchers conducted an in-depth reading of a final list of sixteen documents, which included:

1. 1948 Universal declaration of human rights [52]

2. 1976 UN Convention on Economic Social and Cultural Rights [53]

3. 1981 Convention on the Elimination of all forms of Discrimination Against Women (CEDAW) [54]

4. 1992 World Declaration and Plan of Action for Nutrition [55]

5. 1995 Beijing Declaration and Platform for Action [56]

6. 1996 Rome Declaration on World Food Security [57]

7. 2003 Protocol to the African Charter on Human and Peoples' Rights on the Rights of Women in Africa [58]

8. 2005 Voluntary Guidelines to support the Progressive Realisation of the Right to Adequate Food in the Context of National Food Security [59]

9. 2009 Declaration on the World Food Summit [60]

10. 2012 Global nutrition monitoring framework operational guidance for tracking progress in meeting targets for 2025 [36]

11. 2012 Voluntary Guidelines on the Responsible Governance of Land Tenure of Land, Fisheries and Forests in the Context of National Food Security [61]

12. 2014 Malabo Declaration on Accelerated Agricultural Growth and Transformation for Shared Prosperity and Improved Livelihoods [62]

13. 2014 Rome Declaration on Nutrition [63]

14. 2014 Principles for Responsible Investment in Agriculture and Food Systems [64]

15. 2015 Africa Agenda 2063: The Africa we want. First ten-year implementation plan 2014-2023 [65]

16. 2015 Africa Regional Nutrition Strategy 2015-2025 [66]

17. 2015 Malabo Implementation Strategy and Roadmap to Achieve the 2025 Vision on CAADP [67]

18. 2016 Sustainable Development Goals [68]

These documents were selected because they can be considered the critical guiding frameworks for food and nutrition security globally and in Africa. This list is by no means comprehensive. Rather, it is a sample of conventions to assist us in unpacking how gender can be integrated across the food systems component. The inclusion criteria were the relevance of the document to food systems components, food and nutrition security and gender. Several documents were excluded because they did not meet this criterion. For example, the 2014 Malabo Declaration on Nutrition Security for Improved Economic Growth and Sustainable Development was excluded from the analysis because it did not explicitly mention women or gender.

While some of the documents included in the analysis date back to 1948, they remain relevant to current gender and food systems discourses. For example, the 2030 Sustainable Development Agenda explicitly mentions that the goals and targets are grounded in the 1948 Universal Declaration of Human Rights [53]. This concept of human rights also underpins the introduction of agency as a component of food security, particularly reinforcing principles that underpin the Right to Food [68]. Furthermore, UN and AU member states who are signatories to these agreements and conventions continue to report on the extent to which these commitments have been integrated into national policies and legislation. Examples include: the 2015 South Africa's Beijing +20 Report on the 1995 Beijing Declaration and Platform for Action; 2016 Kenya's Eight Periodic Report on the 1981 CEDAW and 2020 South Sudan's Report on the 1981 CEDAW. The prevailing relevance of these documents is further evidenced by South Sudan's ratification of the 1981 CEDAW in 2015.

The selected documents were uploaded into Atlas-Ti version 8 software. The first author conducted an in-depth reading of all the documents. Quotations were highlighted and allocated code names (subthemes) using specific tools in Atlas-Ti. Themes related to gender equality and the food systems components were identified in each document. 
Similar themes were highlighted using the same code name. The coding process allowed us to determine the number of times a specific theme occurred. These themes were then categorised according to the food systems components to which they best applied. For example, the diet quality of women and girls was classified under the component food environment. Some themes cut across several components of the food system. For example, capacity strengthening cut across all five components. These themes were captured as cross-cutting.

The first author initially identified 38 themes related to gender and food systems. Themes were only coded if a reference to gender was explicit. For example, several documents highlight the importance of improving access to agricultural markets. These sections were only coded if they included reference to women's access to agricultural markets. Themes were coded if they appeared in a document. Frequency of appearance in a single document was not coded. The themes were then reviewed to identify overarching categories. Some themes were merged. For example, fair wages, maternity benefits and increased employment opportunities were classified under the overarching category "employment". Other codes were excluded because their level of significance, relative to other codes, was minimal. For example, alignment and budgeting were coded two times in all 18 documents compared to legislation coded 12 times. Therefore, a code was considered insignificant if mentioned less than three times in the 18 documents. This approach also assisted in reducing subjectivity because the themes were selected based on the number of times they appeared. Some themes appeared several times but could not be categorised in the food system. For example, participation was mentioned in nine of the 18 documents but could not be categorised under any of the food systems components. Such themes were retained to review their relevance to the food system. In the final review, these themes were considered to have a significant bearing on the food system. They were categorised as new components that formed pillars to the effective integration of gender into the food system.

The final analysis included 23 subthemes listed in Table 1 of the results section. Subsequently, an Excel spreadsheet was prepared to summarise the documents that mentioned a specific theme. Another sheet was set up to determine if a specific theme appeared in relation to more than one component of the food system based on the Glopan food systems framework. The second author reviewed all 18 documents to corroborate the themes. Where inconsistencies were found, the authors discussed and reached a consensus. Two more authors reviewed the final themes and validated the categorisation.

Table 1. Summary of main themes.

\begin{tabular}{|c|c|c|c|c|c|c|c|c|c|c|c|c|c|c|c|c|c|c|c|c|}
\hline $\begin{array}{c}\text { Glopan Food Systems } \\
\text { Components }\end{array}$ & Sub-Themes & & & & & & & & Doci & mer & $\mathrm{Nu}$ & nber & & & & & & & & \\
\hline \multirow[t]{2}{*}{$\begin{array}{c}\text { Agricultural } \\
\text { production }\end{array}$} & & 1 & 2 & 3 & 4 & 5 & 6 & 7 & 8 & 9 & 10 & 11 & 12 & 13 & 14 & 15 & 16 & 17 & 18 & Total \\
\hline & $\begin{array}{l}\text { Extension } \\
\text { Land } \\
\text { Water }\end{array}$ & & & $\begin{array}{l}\checkmark \\
\checkmark\end{array}$ & $\begin{array}{l}\checkmark \\
\checkmark\end{array}$ & $\begin{array}{l}\checkmark \\
\checkmark\end{array}$ & $\begin{array}{l}\checkmark \\
\checkmark \\
\checkmark\end{array}$ & $\begin{array}{l}\checkmark \\
\checkmark\end{array}$ & $\begin{array}{l}\checkmark \\
\checkmark\end{array}$ & & & $\checkmark$ & & $\begin{array}{l}\checkmark \\
\checkmark\end{array}$ & $\checkmark$ & $\checkmark$ & & & $\checkmark$ & $\begin{array}{c}5 \\
11 \\
3\end{array}$ \\
\hline Markets and trade & Trade & & & & & $\checkmark$ & $\checkmark$ & $\checkmark$ & & $\checkmark$ & & & & & & & & & $\checkmark$ & 5 \\
\hline $\begin{array}{c}\text { Consumer purchasing } \\
\text { power }\end{array}$ & $\begin{array}{c}\text { Employment } \\
\text { Social protection }\end{array}$ & $\checkmark$ & $\checkmark$ & $\begin{array}{l}\checkmark \\
\checkmark\end{array}$ & $\checkmark$ & $\begin{array}{l}\checkmark \\
\checkmark\end{array}$ & $\checkmark$ & $\checkmark$ & $\checkmark$ & & & & $\checkmark$ & $\checkmark$ & & $\checkmark$ & & & $\begin{array}{l}\checkmark \\
\checkmark\end{array}$ & $\begin{array}{l}9 \\
7\end{array}$ \\
\hline $\begin{array}{l}\text { Food transformation } \\
\text { and consumer demand }\end{array}$ & $\begin{array}{l}\text { Marketing } \\
\text { Processing }\end{array}$ & & & $\checkmark$ & $\checkmark$ & $\checkmark$ & $\begin{array}{l}\checkmark \\
\checkmark\end{array}$ & & & & & & & & & $\checkmark$ & & & & $\begin{array}{l}5 \\
3\end{array}$ \\
\hline Diet quality & $\begin{array}{c}\text { Diet } \\
\text { Maternal and } \\
\text { child health } \\
\text { Water Health and } \\
\text { Sanitation } \\
\text { (WASH) }\end{array}$ & & $\checkmark$ & $\begin{array}{l}\checkmark \\
\checkmark\end{array}$ & $\begin{array}{l}\checkmark \\
\checkmark\end{array}$ & $\checkmark$ & $\begin{array}{l}\checkmark \\
\checkmark\end{array}$ & $\begin{array}{l}\checkmark \\
\checkmark\end{array}$ & $\checkmark$ & $\checkmark$ & $\checkmark$ & & & $\begin{array}{l}\checkmark \\
\checkmark\end{array}$ & & $\checkmark$ & $\begin{array}{l}\checkmark \\
\checkmark\end{array}$ & & $\begin{array}{l}\checkmark \\
\checkmark\end{array}$ & $\begin{array}{c}11 \\
7\end{array}$ \\
\hline
\end{tabular}


Table 1. Cont.

\begin{tabular}{|c|c|c|c|c|c|c|c|c|c|c|c|c|c|c|c|c|}
\hline Cross-cutting & $\begin{array}{c}\text { Agribusiness } \\
\text { Capacity strengthening } \\
\text { Financial resources } \\
\text { Infrastructure } \\
\text { Resource Management } \\
\text { Technology }\end{array}$ & & & $\begin{array}{ll}\checkmark & \checkmark \\
\checkmark & \checkmark \\
& \checkmark \\
& \checkmark\end{array}$ & $\begin{array}{ll}\checkmark & \\
\checkmark & \checkmark \\
\checkmark & \checkmark \\
\checkmark & \\
\checkmark & \checkmark \\
\checkmark & \end{array}$ & $\begin{array}{ll}\checkmark & \\
\checkmark & \checkmark\end{array}$ & $\begin{array}{l}\checkmark \\
\checkmark\end{array}$ & & $\checkmark$ & $\checkmark$ & $\checkmark$ & & $\checkmark \quad \checkmark$ & $\checkmark$ & $\begin{array}{l}\checkmark \\
\checkmark \\
\checkmark \\
\checkmark \\
\checkmark \\
\checkmark\end{array}$ & $\begin{array}{l}5 \\
8 \\
9 \\
4 \\
3 \\
6\end{array}$ \\
\hline Social systems & $\begin{array}{c}\text { Unpaid work } \\
\text { Shared family responsibility } \\
\text { Food culture }\end{array}$ & & & $\begin{array}{ll} \\
\checkmark \\
\checkmark\end{array}$ & $\begin{array}{l}\checkmark \\
\checkmark\end{array}$ & $\begin{array}{lll} & \\
\checkmark & \\
\checkmark & \checkmark\end{array}$ & & & & & & & & & $\begin{array}{l}\checkmark \\
\checkmark\end{array}$ & $\begin{array}{l}4 \\
4 \\
3\end{array}$ \\
\hline Governance & $\begin{array}{c}\text { Gender mainstreaming } \\
\text { Legislation } \\
\text { Participation }\end{array}$ & & $\checkmark$ & $\begin{array}{ll}\checkmark & \checkmark \\
\checkmark & \checkmark \\
\end{array}$ & $\begin{array}{ll}\checkmark & \checkmark \\
\checkmark & \checkmark \\
\checkmark & \checkmark \\
\end{array}$ & $\begin{array}{ll}\checkmark & \\
\checkmark & \checkmark \\
\checkmark & \checkmark \\
\end{array}$ & & $\checkmark$ & $\begin{array}{l}\checkmark \\
\checkmark \\
\checkmark \\
\checkmark\end{array}$ & & & $\begin{array}{l}\checkmark \\
\checkmark\end{array}$ & $\begin{array}{l}\checkmark \\
\checkmark \\
\checkmark\end{array}$ & $\checkmark$ & $\begin{array}{l}\checkmark \\
\checkmark \\
\checkmark \\
\end{array}$ & $\begin{array}{c}7 \\
12 \\
10\end{array}$ \\
\hline Total & & 1 & 4 & 1316 & 2015 & 149 & 4 & 3 & 3 & 2 & 7 & 3 & 114 & 3 & 19 & \\
\hline
\end{tabular}

\section{Results}

A summary of the main themes emerging from the results is available in Table 1. The qualitative analysis assisted us in transforming the text into an organised and concise summary of the results. The texts from the documents were used to identify subthemes that could be categorised under each of the Glopan framework's food systems components. These subthemes are policy options for integrating gender in the food system. The Table 1 indicates the number of documents that mentioned a particular theme. A tick under the document number indicates that the subtheme was mentioned in the document. The results are divided into three sections. Section 3.1 presents results on themes that are exclusive to one component of the Glopan food system. Section 3.2 presents results on themes that cut across several components of the food system. Section 3.3 presents results on themes that are not necessarily part of the food system but significantly influence gender in the food system.

\subsection{Themes Exclusive to One Component of the Food System}

The results presented in this section focus on themes that were exclusive to one component of the food system. The themes are discussed under the components pertaining to each theme.

\subsubsection{Agricultural Production \\ Extension}

Five of the 18 documents assessed referred to extension services. Another four documents referred to the provision of agricultural extension services targeted directly to women. Improving women's access to extension services is an intervention directed at achieving several objectives. First, to increase women's technical proficiency. Second, to provide women with a higher quality of life by reducing poverty. Third, to strengthen women's vital role in food security. Fourth, to ensure gender-equal opportunities. Only the Beijing Declaration and Platform for Action mentions increasing the proportion of women extension workers.

Land

Land was mentioned in eleven documents. Women's secure and equal access to and control over land was emphasised. Six documents prioritised the development of legislation on women's right to own land and other forms of property. The Voluntary Guidelines on the Right to Food propose that legislation protect women's full and equal right to own land and other property. This legislation should be aligned with legal and other policy mechanisms that align with international human rights obligations.

Water

Three documents referred to women's secure and equal access to water. Water was described as a natural resource that could be used to enhance agricultural productivity. 
The documents referred mainly to women's access to and control over this scarce resource. The Rome Declaration on World Food Security referred to women's participation in the conservation of water.

\subsubsection{Market and Trade Systems}

Access to Markets and Trade

Markets and trade were mentioned in five documents. The declaration on the World Food Summit and the SDGs mentioned that improving women's market access was imperative to double agricultural productivity by 2030. Women's access to domestic, regional and international markets was prioritised. Focus on women's needs concerning the dissemination of market and trade information was highlighted. Emphasis was placed on training to capacitate women in these fields. Specific reference was made to reducing the adverse effects of trade policies on women, particularly on new and traditional economic activities driving food security.

\subsubsection{Consumer Purchasing Power Employment}

Employment was mentioned in nine documents. Areas of prioritisation included fair wages and equal remuneration, rights and working conditions for women relative to men. Maternity leave was highlighted, focusing specifically on establishing legislation to ensure that women can take maternity leave without fear of losing their jobs. Emphasis was placed on increasing women's access to opportunities to pursue employment, especially non-farm employment. Men and women should be subjected to the same criteria of selection for employment. Several documents propose the establishment of legislation to legalise these commitments. Training and skills development for girls was also emphasised as a measure to increase employment opportunities.

\section{Social Protection}

Social protection was mentioned in seven documents. Specific reference was made to social protections for mothers and children. Emphasis was placed on legislative measures to support maternity leave with pay or comparable social benefits without loss of employment. The Beijing Declaration and Platform for Action and the CEDAW encouraged social support services to support parents in balancing family and work responsibilities. The establishment of high-quality, flexible and affordable child-care facilities was proposed as an example in the Beijing Declaration and Platform for Action. The Voluntary Guidelines on the Right to Food suggests channelling food assistance through women to increase their household decision-making role, particularly in relation to decisions concerning food.

\subsubsection{Food Transformation and Consumer Demand Marketing}

Marketing was referred to in five documents. Women's equal access to marketing facilities, training and services at the local and community levels was emphasised. The documents generally promote women's participation in enterprises, particularly those involved in food production. States are encouraged to facilitate networking and the exchange of information, particularly amongst women entrepreneurs. The World Declaration and Plan of Action emphasises the potential of research to promote the role of women in all aspects of food production, including marketing.

\section{Processing}

Three documents mention processing. Agenda 2063 prioritises leveraging skilled women entrepreneurs in agro-processing value chains. The World Declaration and Plan of Action for Nutrition suggests investing in research that prioritises women's involvement in processing activities. The Rome Declaration on World Food Security emphasises gender equal opportunities for education and training in food processing. 


\subsubsection{Diet Quality \\ Diet Quality of Women and Girls}

Issues related to the diet quality of women and girls were mentioned in 11 documents, marking the highest number of mentions across the 18 documents. Specific reference was made to monitoring micronutrient deficiencies in women. A range of targets, especially on iron deficiency anaemia and reduction in hunger in women, were proposed. The nutritional needs of adolescent girls were emphasised. The role of women in improving nutrition within the household was mentioned. Women's access to safe and nutritious food was also prioritised.

\section{Maternal and Child Health}

Maternal and child health was mentioned in seven documents. Generally, the documents emphasised access to nutritious food by children under five, pregnant women and lactating mothers. The Rome Declaration on Nutrition encourages a focus on the first thousand days by supporting adequate care and feeding practices. The World Declaration and Plan of Action for Nutrition emphasises preventing food-borne and water-borne diseases and other infections by supporting exclusive breastfeeding for the first six months of a child's life.

\section{WASH}

Concerning water, health and sanitation, reference was made in the CEDAW and the Protocol to the African Charter on Human and People's Rights on the Rights of Women in Africa to the state's obligation to ensure the progressive realisation of women's access to safe drinking water. The SDGs prioritise access to adequate and equitable sanitation and hygiene for open defecation with particular attention to the needs of women and girls. The Beijing Declaration and Platform for Action and the World Declaration and Plan of Action for Nutrition also emphasises women's access to safe drinking water and environmental sanitation, including waste disposal systems. This subtheme was mentioned in five documents.

\subsection{Themes Cutting across Several Food Systems Components}

This section presents results on themes that cut across several components of the food system. Table 2 below provides a summary of these themes and the food systems components each theme cuts across. A tick indicates that the theme was mentioned with reference to the specific component of the food system. Capacity strengthening and resource management were the only two themes that cut across all five food system components.

Table 2. Summary of cross-cutting themes and their related food systems components.

\begin{tabular}{|c|c|c|c|c|c|c|}
\hline \multirow[b]{2}{*}{ Subthemes } & \multicolumn{6}{|c|}{ Food Systems Components } \\
\hline & $\begin{array}{l}\text { Agricultural } \\
\text { Production }\end{array}$ & $\begin{array}{c}\text { Market and } \\
\text { Trade } \\
\text { Systems }\end{array}$ & $\begin{array}{l}\text { Consumer } \\
\text { Purchasing } \\
\text { Power }\end{array}$ & $\begin{array}{l}\text { Food Transformation } \\
\text { and Consumer Demand }\end{array}$ & $\begin{array}{c}\text { Diet } \\
\text { Quality }\end{array}$ & TOTAL \\
\hline Capacity strengthening & $\checkmark$ & $\checkmark$ & $\checkmark$ & $\checkmark$ & $\checkmark$ & 5 \\
\hline Financial resources & $\checkmark$ & $\checkmark$ & $\checkmark$ & & & 3 \\
\hline Infrastructure & $\checkmark$ & $\checkmark$ & $\checkmark$ & & & 3 \\
\hline Resource management & $\checkmark$ & $\checkmark$ & $\checkmark$ & $\checkmark$ & $\checkmark$ & 5 \\
\hline Technology & $\checkmark$ & $\checkmark$ & $\checkmark$ & $\checkmark$ & & 4 \\
\hline
\end{tabular}

\subsubsection{Agribusiness}

Themes related to agribusiness were mentioned in five documents. Agribusiness was mentioned in relation to agricultural production, market and trade systems, consumer purchasing power and food transformation and consumer demand. No documents mentioned 
the role of agribusiness in improving quality diets. In general, the documents prioritised the entry of women into agricultural enterprises at the production, market and trade and processing stages. Emphasis was placed on women's entry into agricultural value chains.

\subsubsection{Capacity Strengthening}

Capacity strengthening of women in food systems related activities was mentioned in eight documents. Capacity strengthening was mentioned in relation to all five components of the food systems. Specific areas of capacity strengthening included nutrition, technology use, business, climate change, resource management, food production, processing and marketing. The Rome Declaration on World Food Security emphasised the increased proportion of women in skills development systems.

\subsubsection{Financial Resources}

Financial resources were mentioned in nine documents. Financial resources were mentioned in relation to agricultural production, market and trade systems and consumer purchasing power. Financial access focused specifically on women's access to agricultural credit and loans on easy terms at the local and community levels, the right to own a bank account and access to financial services. Agenda 2063 emphasised women's access to finance to enable them to graduate from the informal sector to the small and micro-enterprise sector. The Beijing Declaration and Platform for Action emphasises non-traditional and mutual credit schemes and the development of innovative linkage with financial institutions to promote women's entrepreneurship. It also proposes offering incentives to the banking sector to develop services targeted at women. Several [3] documents emphasised not only access but also control over financial resources.

\subsubsection{Infrastructure}

Infrastructure was mentioned in three documents in relation to agricultural production, market and trade systems and consumer purchasing power. The SDGs promote the development of infrastructure to promote shared responsibility within the household. The Beijing Declaration and Platform for Action promotes women's equal access to transportation to support food production activities. It also prioritises economic infrastructure, including water and sanitation, electrification, transport and road construction to improve women's access to jobs and contracts. Such infrastructure could also reduce the time women spend collecting water and firewood. Public infrastructure to support women's access to markets is also highlighted in the same document as a means to support women's income and their access to markets to buy food.

\subsubsection{Resource Management}

Resource management was mentioned in four documents in relation to all five components of the food system. Emphasis was placed on strengthening women's participation in resource management, particularly women's participation in policy decision-making. Drawing on women's indigenous knowledge of resource management was highlighted as critical. The Beijing Declaration and Platform for Action encourages mainstreaming a gender perspective in the design and implementation of sustainable resource management. This includes an understanding of the impacts of environmental degradation on women.

\subsubsection{Technology}

Six documents mention technology in relation to agricultural production, market and trade systems, consumer purchasing power and food transformation and consumer demand. In general, the documents promoted women's access to appropriate technologies. The SDGs explicitly highlight enhancing the use of enabling technology, especially information communications technology, to empower women. Three documents also encourage the use of technology in reducing environmental degradation and mitigating the impacts of climate change. The Beijing Declaration and Platform for Action emphasises women's 
equal access to technology to increase women's incomes and promote household food security. The World Declaration and Plan of Action for Nutrition emphasises the need for research and extension on time and energy-saving agricultural devices to reduce women's workload. The Beijing Declaration and Platform for Action specifically encourages the development of appropriate productive and domestic labour-saving technologies.

\subsection{Themes Influencing Gender in the Food System}

Across the 18 documents, the authors identified several themes concerning gender and food systems that did not necessarily apply to any of the food systems components but are essential for integrating gender appropriately in the food system. These sub-themes were categorised under the headings Social Systems and Governance. While some of these themes could be placed under a specific food systems component, they were more appropriate in the categories discussed below.

\subsubsection{Social Systems}

Social systems have a bearing on how gender is incorporated in the food system and can significantly influence the optimal functionality of the food system. Sub-themes related to social systems included unpaid work, shared family responsibility and food culture.

Unpaid Work

Unpaid work was mentioned in four documents and cut across all five components of the food system. In general, the documents highlight that women are involved in care work and other domestic activities, preventing them from pursuing agricultural, marketing and other activities to increase their income. While this work is non-monetised, it plays a significant role in the survival of households and families. The Protocol to the African Charter on Human and People's Rights on the Rights of Women in Africa highlight the importance of taking the necessary measures to recognise the value of women's work in the home. Measures included in the SDGs include the provision of public services, infrastructure and social protection.

Shared Family Responsibility

Shared family responsibility was mentioned in four documents and was also regarded as a measure to overcome women's unpaid work. Shared family responsibility did not relate to any of the food systems components but could significantly influence women's access to many of the services and resources promoted across other elements of the food system. In general, the documents emphasise that caring and maintaining the household are responsibilities that both men and women should carry out. The Protocol to the African Charter on Human and People's Rights on the Rights of Women in Africa explicitly highlight that both parents bear responsibility for the upbringing and development of children. The Beijing Declaration and Platform for Action encourages media campaigns that demystify gender stereotypes related to the role of men and women in the family. The World Declaration and Plan of Action for Nutrition proposes encouraging men to fully participate and take responsibility for the nutritional well-being of their families.

\section{Food Culture}

Food culture was mentioned in three documents and mainly related to food transformation, consumer demand and diet quality. Food culture emphasises the cultural values of dietary and eating habits in different cultures, particularly in relation to pregnant and lactating women. The World Declaration and Plan of Action for Nutrition encourages the development and implementation of public information campaigns to promote the fair distribution of food resources irrespective of sex, age and other characteristics. It also highlights the role of mass media in demystifying harmful food taboos. 


\subsubsection{Governance}

Governance emerged as a critical theme related to gender and food systems. While governance issues could be allocated to specific components of the food system, the significance of this theme required including it as a stand-alone theme. Sub-themes under governance included gender mainstreaming, legislation, participation and targets.

\section{Gender Mainstreaming}

Gender mainstreaming was mentioned in seven documents. In general, the five documents promoted the integration of a gender perspective in all policies, legislation development plans and programmes. The SDGs promote gender mainstreaming at national, regional and international levels. The Beijing Declaration and Platform for Action emphasises strengthening gender analysis capacities.

\section{Legislation}

Legislation was mentioned in 12 documents and also cut across all components of the food system. In general, the documents promote the enactment and enforcement of legislation related to equal pay for men and women, maternity leave and other social protection measures, women's rights to employment, full participation in the economy, land, breastfeeding and owning and operating a bank account. The CEDAW specifically promotes legislation on social support services to enable parents to combine family obligations with work. The protocol to the African Charter on Human and People's Rights on the Rights of Women in Africa promotes legislation on women's right to adequate and nutritious food. The Rome Declaration on World Food Security encourages the development of gender-sensitive legislation to enable women to have equal access to and control over credit, land, water and other productive resources.

\section{Participation}

Participation was mentioned in ten documents and cut across several components of the food system. In general, the documents emphasised women's involvement in the development and implementation of policies and programmes. Several documents emphasised women's participation in decision-making about political, economic and public life at all levels. The Voluntary Guidelines on the Right to Food promotes women's active participation in all aspects of agricultural and food production strategies. The Beijing Declaration and Platform for Action explicitly highlights the inclusion of women in leadership positions at all levels of decision-making.

\section{Discussion}

This discussion draws on the results to propose an enhanced Glopan framework for integrating gender in the food system. The elements of the new framework presented in Figure 2 below, the 'Framework for integrating gender in the food system', guide the discussion. We begin by discussing the inner five circles that highlight proposed gender policy actions in the Glopan food systems framework components. We then discuss the outer circle, which presents themes that need to integrate gender across all the food system components. We highlight how several cross-cutting actions are necessary to support women's effective participation in the food system. We then highlight access and control as factors that influence women's ability to participate in the food system. Governance and social systems are introduced as two pillars that are essential for the food system to function optimally, highlighting the proposed themes identified for each of these pillars. Finally, we highlight gaps in the proposed framework.

The inner circle proposes policy actions to integrate gender in agricultural production, market access and trade, consumer purchasing power, food transformation and consumer demand and diet quality. Generally, the findings on gender policy actions to integrate gender in the food systems components are consistent with the literature. While some of the documents assessed date back to the early 1990s, current literature indicates that 
many of the same challenges, such as women's unequal access to resources, persist. For example, gender policy actions in agriculture production focus on efforts to improve women's agricultural productivity. The findings indicate that women's access to extension services, land and water are essential. This finding is consistent with the vast literature on improving women's agricultural productivity $[8,69,70]$. Inequalities in access to agricultural resources and services widen the gender gap in agricultural productivity [32,71]. Land was mentioned in 11 documents, indicating the essential role of women's access to and control over land. This finding is consistent with the literature as women's land tenure continues to constrain food security and nutrition. Furthermore, large-scale land transfers increase women's poverty and have implications for women's health and well-being [27].

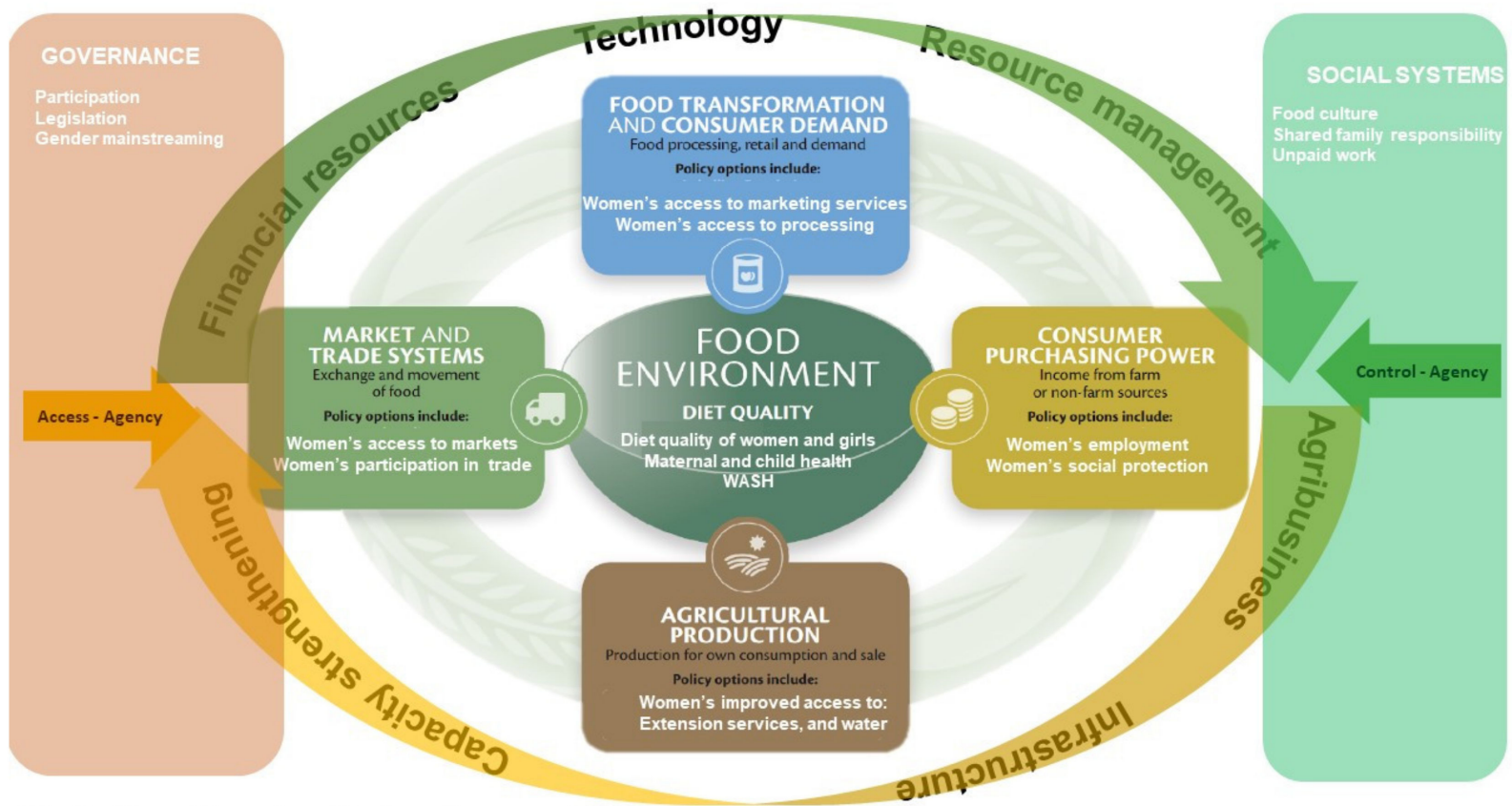

Adapted from Glopan Food Systems Framework (Glopan, 2016)

Figure 2. Framework for integrating gender in the food system. (Source: Adapted from the 2014 Glopan food systems framework [13]).

While improving women's agricultural productivity is critical, their control over harvests and agricultural outputs is often undermined by gender norms. Bezner-Kerr et al.'s study in Northern Malawi [4] indicates that women were actively involved in production, in some cases, without support from their partners. However, harvests were taken and sold by men who often used the income generated for alcohol consumption rather than to benefit the household. A gap in these commitments concerns women's control of agricultural outputs.

The literature suggests that gender divisions of labour and social norms limit women's participation in market and trade systems [23,32,33,72]. Women's time constraints prevent them from fully participating in market and trade systems. Traditional gender divisions of labour allocate market responsibilities to men, with women participating in informal trade of surpluses they produce within the homestead [20]. Two key actions were identified under the market and trade systems component: improving women's access to markets and trade. In particular, improving women's access to markets and market information was emphasised. Increasing women's ability to participate in domestic, regional and international trade was also highlighted. However, one critical oversight was the intersection of gender roles and relations with women's access to markets and trade systems. Access to transportation, cultural restrictions on women's mobility and increased time pressures are all gender norms that prevent women from fully participating in, and benefitting from, market and trade systems [20]. These systemic inequalities are reproduced through social 
and cultural norms. Interventions developed to increase women's market access need to take into account the context-specific gender realities of women.

Consumer purchasing power emphasised women's employment and social protection. Frequently, women's socially constructed roles prevent them from pursuing formal employment. Time spent looking after children and other family members, cooking, cleaning and collecting firewood and water constrains women's ability to seek and secure employment. Consistent with the literature $[73,74]$, the findings suggest that social protection programmes that address time constraints could offer women buffers that enable them to pursue employment and other opportunities. Some of the legal documents also provide scope for women to exercise their right to equal pay. However, one critical oversight is access to information on rights and mechanisms to empower them to exercise these rights.

Gender policy actions proposed for food transformation and consumer demand emphasised women's participation in processing and marketing. Processing referred to women's involvement in adding value to products to increase the nutritional value and ultimately the demand for these products. Women's capacity to market these improved products was also emphasised. Marketing referred to the development of women's enterprises. While many of the documents emphasised strengthening women's capacity in value-addition, less emphasis was placed on the gender norms that inform consumer demand for nutritious food. Okello et al. [24] suggest that women are often the recipients of nutrition information. Therefore, they are more likely to demand nutritious food. However, while women hold primary responsibility for food preparation, they are not responsible for all the choices involved in preparing food [20]. This literature suggests that more efforts are needed to understand the gender dynamics associated with the demand for nutrient-rich food. Efforts might include offering men nutrition education.

Women's role in improving household and children's diet quality remains one of the critical areas of intervention. From the analysis, improving the diet quality of women and girls, maternal and child health and WASH were proposed as gender policy actions to integrate gender in the food system. This finding is also evidenced by the significant number of indicators [36] on women and quality diets. This finding is consistent with the vast literature on maternal and child nutrition and health [38-41]. The heavy workloads women carry mean that they typically have high nutrient requirements. Coupled with biological factors such as menstruation, pregnancy and lactation, women and girls' dietary needs frequently surpass men's [6]. The emphasis on women's access to quality diets is necessary. Access to the right information, as well as improved diets, could improve women's productivity as well as girl's capacity to participate actively in school. However, targeting only women in household and child nutrition could reinforce the notion that food and nutrition are women's responsibility. Such an overemphasis overlooks the complementary role of men and reinforces women's role in unpaid care work [72,75].

The outer circle of Figure 2 represents the cross-cutting gender actions. Women's involvement in agribusiness, capacity strengthening, financial resources, infrastructure, resource management and technology were highlighted as priorities related to several food system components. These cross-cutting actions are opportunities to support women's participation in several components of the food system. For example, improving water infrastructure could reduce the amount of time women spend collecting water, increasing the time they have to pursue agricultural production or other activities to strengthen their consumer purchasing power. Again, access and control remain essential to ensure that women can optimally participate in all activities. The documents overlook one critical crosscutting element that relates to resource management. The literature indicates that climate change has significant implications for and impacts on gender equality [11]. Women's limited access to and control over natural resources frequently constrains their ability to adapt to climate change. Climate change also increases women's work burden [76]. These feedback loops widen gender inequalities between men and women. While the term climate change emerged after many of these documents were adopted, a gap was observed in the more recent documents related to gender and climate change policy actions. 
Many of the actions in the inner circles and the cross-cutting issues emphasise access. However, access is not enough [70]. Women should also be capacitated to control extension service outcomes, land, water, markets, finances and technologies. Altering the context which constrains choice or agency is vital in agricultural work [74]. Women's ability to retain control and decision-making power over resources and services is essential. For example, in low-income countries, control over income and other household resources is frequently dominated by men. Consequently, while programmes may target women, they may not be able to effectively use resources or training because of gender norms that limit their capacity to make decisions [32]. The two arrows on either side of the cross-cutting issues indicate the importance of simultaneously addressing barriers to access and control. This paper proposes articulating issues of access and control as agency.

The 2020 HLPE report introduced agency as a new pillar for defining food security. The term is defined as people's ability to make decisions concerning food, how they access it and their participation in processes that shape the food system [6]. As this concept of food systems evolves, agency needs to be appropriately conceptualised and integrated. Women play multiple roles in society, including caregiving, producing food and looking after the home. However, their participation and ability to make decisions within the food system is often constrained by socially entrenched beliefs about men and women's roles and relationships [74].

Much of the literature on gender has focused on women's role in the production and food environment components of the food system, with little attention on the marketing, food transformation and consumer purchasing power elements. Women have been emphasised, overlooking gender relations that inform men and women's participation in the food system [20]. Our analysis indicates that the documents used in this assessment perpetuate an over-emphasis on women, with few documents highlighting policy priorities for addressing gender relations between men and women. Nonetheless, the need to address social systems was identified as a thematic area. The framework we propose incorporates governance and social systems as core pillars for integrating gender in the food system. Participation, legislation, targeting and gender mainstreaming were all emphasised in the 18 documents. These themes suggest that the formal governance systems that underpin food systems also need to be considered.

Men and women's participation at all levels of food systems governance, from global to community, needs to be prioritised in all the food system elements. This finding is consistent with the introduction of agency as a new component of food security [6].

Legislation to offer men and women an avenue to exercise their rights needs to be established. The fact that legislation was mentioned in ten of the 18 documents indicates that a demand exists for policies related to gender and food systems to become legally binding. Legislating gender issues related to the food system ensures that enforcement measures can be put in place. Gender mainstreaming has been a priority since the 1995 Beijing Declaration and Platform for Action and continues to be a priority across many of the documents assessed. Social systems refer to societal expectations and pressures that undermine women's participation in the food system. These include food culture, shared family responsibility and unpaid work. The results indicated that many of these actions were global policy priorities since the signing of the 1992 World Declaration and Plan of Action on Nutrition. These actions have again become a priority through the SDGs. Social systems do not fall under a specific food system component, but they are important factors for ensuring that the food system functions optimally. The social systems gender policy actions offer opportunities to address some of the constraints women face in participating in and benefiting from the food system. For example, much of the literature on food systems emphasise women's nutrition and the role of women in children's nutrition. While this is indeed important, the overemphasis on women overlooks the dynamism of gender [7] and the need to understand and expand men's roles. Opportunities to leverage men's shared responsibility in providing quality diets are neglected [72]. 
Evidence from Malawi suggests that men are becoming increasingly involved in children's nutrition and participating in housework [77]. Opportunities to redistribute unpaid care work exist. Men's shared responsibility in the household could increase the time women have to pursue activities in at least three food systems components. Similarly, working with men to share control over household resources and decision-making power could improve women's access and control over the resources, training, capacity building and other services proposed as policy actions [49].

As the Global Food Systems Summit approaches, integrating gender into the food system must remain central to the discussion. Often integrating gender is a tick box exercise for many policymakers. Our findings suggest that gender-related food systems challenges have persisted regardless of the numerous gender commitments that exist. Understanding the interconnectedness of the food systems is essential to ensure that we leverage positive outcomes in one sector and apply them to another. Policies that tackle one aspect of the food system without a holistic understanding of the trade-offs and consequences of the policies on other domains could perpetuate and further exacerbate inequalities. For example, as Patel et al. (2015) [14] argue, increasing maternity leave could improve women's ability to exclusively breastfeed, thereby improving child nutrition. However, this also increases women's reproductive work and perpetuates the notion that women should be responsible for child nutrition. The proposed framework offers a lens to assist researchers, policymakers and other food systems stakeholders to begin exploring trade-offs and leverage points for transforming gender inequalities using a systems approach.

The framework also emphasises agency and the participation of women in decisionmaking in private and public spaces. Patel et al. [14] point to the value of ensuring that community's perspectives are integrated into policy development by highlighting that communities understand causes and responses to food systems challenges that policymakers and other stakeholders cannot. While the agreements and commitments that we include in this assessment are essential to global development, we cannot ignore that the communities they govern are not passive recipients of policy. They engage and respond to initiatives in different ways, and these responses are gender in nature and have important implications for food systems outcomes.

\section{Conclusions}

The in-depth analysis of the 18 documents led to the identification of 24 gender policy actions that inform how gender can be integrated into the Glopan food system framework. While the frameworks and agreements included in this paper offer a body of evidence for integrating gender in some of the components of the food system, many of the interventions proposed address the symptoms and not the root causes of inequality [78]. The introduction of the two pillars of governance and social systems to this framework attempts to address some of the underlying systems that underpin gender inequality. The framework provides a foundation for exploring the trade-offs women make to participate in various segments of the food system. Feedback loops that reinforce inequalities across various food systems components can also be explored. Further studies on such frameworks may include the Paris Agreement [79] to ensure that the proposed framework addresses gaps in climate change. The Glopan framework in itself lacks explicit components related to climate change.

Critical to applying this framework is conducting a gender analysis that accounts for different contexts and different gender groups. Social, economic and cultural contexts need to form an integral component of how gender is incorporated into food systems approaches. Njuki [80] reminds us that women and men are not homogenous. Even within the same community, women's needs may differ by age, race, class and other factors. The heterogeneity of different gendered groups needs to be considered when developing interventions that aim to address inequalities.

The paper unearths a demand for more gender and food systems research and literature. No documents were identified that offer a gender lens for integrating gender in the food system. The framework proposed in this paper is an initial attempt to frame gender 
within the context of the food system. Further research is needed to understand how the proposed gender policy actions are inter-connected and present barriers or opportunities for women's participation and benefits in the food system.

Author Contributions: Conceptualization, E.M.; methodology, E.M.; validation, E.M. and E.B.; formal analysis, E.M. and E.B.; data curation, E.M.; writing—original draft preparation, E.M.; writing—review and editing E.M., M.M.-C., M.N.M. and E.B.; visualization, E.M. All authors have read and agreed to the published version of the manuscript.

Funding: This research received no external funding.

Institutional Review Board Statement: Not applicable.

Informed Consent Statement: Not applicable.

Acknowledgments: We would like to thank Mywish Maredia for her comments on the paper.

Conflicts of Interest: The authors declare no conflict of interest.

\section{References}

1. FAO; IFAD; UNICEF; WFP; WHO. The State of Food Security and Nutrition in the World 2020: Transforming Food Systems for Affordable Healthy Diets; FAO: Rome, Italy, 2020.

2. AUC. CAADP Toolkit Addis Ababa: AUC. 2020. Available online: https://au.int/en/caadp/toolkit (accessed on 7 December 2020).

3. Schipanski, M.E.; MacDonald, G.K.; Rosenzweig, S.; Chappell, M.J.; Bennett, E.M.; Kerr, R.B.; Blesh, J.; Crews, T.; Drinkwater, L.; Lundgren, J.G.; et al. Realizing Resilient Food Systems. Bioscience 2016, 66, 600-610. [CrossRef]

4. Bezner, K.R.; Hickey, C.; Lupafya, E.; Dakishoni, L. Repairing rifts or reproducing inequalities? Agroecology, food sovereignty, and gender justice in Malawi. J. Peasant Stud. 2019, 46, 1499-1518.

5. Lemke, S. Empowered Women and the Need to Empower Men: Gender Relations and Food Security in Black South African Households. Stud. Tribes Tribals 2003, 1, 59-67. [CrossRef]

6. HLPE. Food Security and Nutrition: Building a Global Narrative towards 2030. A Report by the High Level Panel of Experts on Food Security and Nutrition of the Committee on World Food Security; CFS: Rome, Italy, 2020.

7. Verhart, N.; van den Wijngaart, A.; Dhamankar, M.; Danielsen, D. Bringing Agriculture and Nutrition Together Using a Gender Lens; Royal Tropical Institute (KIT) and Netherlands Development Organisation (SNV): Amsterdam, The Netherlands, 2016.

8. IFC. Investing in Women along Agribusiness Value Chains; World Bank: Washington, DC, USA, 2016.

9. HLPE. Nutrition and Food Systems. A Report by the High Level Panel of Experts on Food Security and Nutrition of the Committee on World Food Security; Committe on World Food Security (CFS): Rome, Italy, 2017.

10. Cislaghi, B.; Heise, L. Gender norms and social norms: Differences, similarities and why they matter in prevention science. Sociol. Health Illn. 2020, 42, 407-422. [CrossRef]

11. Vercillo, S. The complicated gendering of farming and household food responsibilities in northern Ghana. J. Rural Stud. 2020, 79, 235-245. [CrossRef]

12. Agarwal, B. Bargaining and Gender Relations: Within and Beyond the Household. Fem. Econ. 1997, 3, 1-51. [CrossRef]

13. Global Panel on Agriculture and Food Systems for Nutrition. How Can Agriculture and Food Systems Policies Improve Nutrition; Glopan: London, UK, 2014.

14. Patel, R.; Kerr, R.B.; Shumba, L.; Dakishoni, L. Cook, eat, man, woman: Understanding the New Alliance for Food Security and Nutrition, nutritionism and its alternatives from Malawi. J. Peasant Stud. 2015, 42, 21-44. [CrossRef]

15. Caron, C. Gendering work and labor in the agriculture sector: A focus on South Asia. In Handbook on Gender in Asia; Ruwanpura, K.N., Huang, S., Eds.; Edward Elgar Publishing: Cheltenham, UK, 2020; pp. 185-202.

16. Doss, C.; Meinzen-Dick, R.; Quisumbing, A.; Theis, S. Women in agriculture: Four myths. Glob. Food Secur. 2018, 16, 69-74. [CrossRef]

17. Garcia, A.S.; Wanner, T. Gender inequality and food security: Lessons from the gender-responsive work of the International Food Policy Research Institute and the Bill and Melinda Gates Foundation. Food Secur. 2017, 9, 1091-1103. [CrossRef]

18. Den Boer, A.C.L.; Kok, K.P.W.; Gill, M.; Breda, J.; Cahill, J.; Callenius, C.; Caron, P.; Damianova, Z.; Gurinovic, M.; Lahteenmaky, L.; et al. Research and innovation as a catalyst for food system transformation. Trends Food Sci. Technol. 2021, 107, 150-156. [CrossRef]

19. Gillespie, S.; Bold, M.V.D. Agriculture, Food Systems, and Nutrition: Meeting the Challenge. Glob. Chall. 2017, 1, 1600002. [CrossRef]

20. Twynman, J.; Talsma, E.F.; Konstantina, T.; Chiara, F.; Inge, B. Gender Equity Considerations in Food Environments of Low and Middle Income Countries; International Food Policy Research Institute (IFPRI): Washington, DC, USA, 2020.

21. Béné, C.; Oosterveer, P.; Lamotte, L.; Brouwer, I.D.; de Haan, S.; Prager, S.D.; Talsma, E.F.; Khoury, C.K. When food systems meet sustainability-Current narratives and implications for actions. World Dev. 2019, 113, 116-130. [CrossRef] 
22. Bonatti, M.; Borba, J.; Schlindwein, I.; Rybak, C.; Sieber, S. They Came Home Over-Empowered: Identifying Masculinities and Femininities in Food Insecurity Situations in Tanzania. Sustainability 2019, 11, 4196. [CrossRef]

23. Ambikapathi, R.; Shively, G.; Leyna, G.; Mosha, D.; Mangara, A.; Patil, C.L.; Boncyk, M.; Froese, S.L.; Verissimo, C.K.; Kazonda, P.; et al. Informal food environment is associated with household vegetable purchase patterns and dietary intake in the DECIDE study: Empirical evidence from food vendor mapping in peri-urban Dar es Salaam, Tanzania. Glob. Food Secur. 2021, $28,100474$. [CrossRef] [PubMed]

24. Okello, J.; Hutchinson, M.; Mwang'Ombe, A.; Ambuko, J.; Olubayo, F.; Mwakangalu, M. Consumer Demand for Value-added Products of African Indigenous Vegetables in Coastal Kenya: The Case of Sun-dried and Frozen Cowpea Leaves. J. Agric. Food Syst. Community Dev. 2015, 2015, 189-207. [CrossRef]

25. Burke, W.J.; Li, S.; Banda, D. Female access to fertile land and other inputs in Zambia: Why women get lower yields. Agric. Hum. Values 2018, 35, 761-775. [CrossRef]

26. Giroud, A.; Huaman, S.J. Investment in agriculture and gender equality in developing countries. Transnatl. Corp. 2019, 26, 89-113.

27. Nyantakyi-Frimpong, H.; Kerr, R.B. Land grabbing, social differentiation, intensified migration and food security in northern Ghana. J. Peasant Stud. 2017, 44, 421-444. [CrossRef]

28. Hajjar, R.; Ayana, A.N.; Rutt, R.; Hinde, O.; Liao, C.; Keene, S.; Bandiaky-Badji, S.; Agrawal, A. Capital, labor, and gender: The consequences of large-scale land transactions on household labor allocation. J. Peasant Stud. 2020, 47, 566-588. [CrossRef]

29. Bargain, O.; Kwenda, P.; Ntuli, M. Gender Bias and the Intrahousehold Distribution of Resources: Evidence from African Nuclear Households in South Africa. WIDER Working Paper, No. 2017/71; United Nations University World Institute for Development Economics Research (UNU-WIDER): Helsinki, Finland, 2017.

30. Kihiu, E.N.; Amuakwa-Mensah, F. Agricultural market access and dietary diversity in Kenya: Gender considerations towards improved household nutritional outcomes. Food Policy 2020, 100, 102004. [CrossRef]

31. De Groot, J.; Mohlakoana, N.; Knox, A.; Bressers, H. Fuelling women's empowerment? An exploration of the link-ages between gender, entrepreneurship and access to energy in the informal food sector. Energy Res. Soc. Sci. 2017, 28, 86-97. [CrossRef]

32. Bamber, P.; Startiz, C. The Gender Dimensions of Global Value Chains; International Centre for Trade and Sustainable Development (ICTSD): Geneva, Switzerland, 2016.

33. Nchanji, E.B.; Collins, O.A.; Katungi, E.; Nduguru, A.; Kabungo, C.; Njuguna, E.M.; Ojiewo, C. What Does Gender Yield Gap Tell Us about Smallholder Farming in Developing Countries? Sustainability 2020, 13, 77. [CrossRef]

34. Gido, E.O.; Ayuya, O.I.; Owuor, G.; Bokelmann, W. Consumer Acceptance of Leafy African Indigenous Vegetables: Comparison Between Rural and Urban Dwellers. Int. J. Veg. Sci. 2017, 23, 346-361. [CrossRef]

35. Komatsu, H.; Malapit, H.; Balagamwala, M. Gender effects of agricultural cropping work and nutrition status in Tanzania. PLoS ONE 2019, 14, e0222090. [CrossRef] [PubMed]

36. WHO. Global Nutrition Monitoring Framework: Operational Guidance for Tracking Progress in Meeting Targets for 2025; WHO: Geneva, Switzerland, 2012.

37. WHO. The Lancet Series on Maternal and Child Undernutrition. Available online: https://www.who.int/nutrition/publications/ lancetseries_maternal_and_childundernutrition/en/\#: \{\}:text=The $\% 20$ Lancet $\% 20$ have $\% 20$ published $\% 20$ a, on $\% 20 \mathrm{Maternal} \%$ 20and $\% 20$ Child $\% 20$ Undernutrition.\&text=The $\% 20$ World $\% 20$ Health $\% 20$ Organization $\% 20$ regards, million $\% 2 C \% 20$ are $\% 20 \mathrm{due} \%$ 20to\%20undernutrition (accessed on 12 April 2021).

38. Black, R.E.; Allen, L.H.; Bhutta, Z.A.; Caulfield, L.E.; De Onis, M.; Ezzati, M.; Mathers, C.; Rivera, J. Maternal and Child Undernutrition Study Group. Maternal and child undernutrition: Global and regional exposures and health consequences. Lancet 2008, 371, 243-260. [CrossRef]

39. Gewa, C.A.; Oguttu, M.; Yandell, N.S. Maternal nutrition in rural Kenya: Health and socio-demographic determinants and its association with child nutrition. Matern. Child Nutr. 2012, 8, 275-286. [CrossRef]

40. Ali, Z.; Saaka, M.; Adams, A.-G.; Kamwininaang, S.K.; Abizari, A.-R. The effect of maternal and child factors on stunting, wasting and underweight among preschool children in Northern Ghana. BMC Nutr. 2017, 3. [CrossRef]

41. Debela, B.L.; Gehrke, E.; Qaim, M. Links between Maternal Employment and Child Nutrition in Rural Tanzania. Am. J. Agric. Econ. 2021, 103, 812-830. [CrossRef]

42. Walters, C.N.; Rakotomanana, H.; Komakech, J.J.; Stoecker, B.J. Maternal determinants of optimal breastfeeding and complementary feeding and their association with child undernutrition in Malawi (2015-2016). BMC Public Health 2019, 19. [CrossRef]

43. Kruger, A.; Lemke, S.; Phometsi, M.; Riet, H.V.; Pienaar, A.E.; Kotze, G. Poverty and household food security of black South African farm workers: The legacy of social inequalities. Public Health Nutr. 2006, 9, 830-836. [CrossRef]

44. Regassa, N.; Stoecker, B.J. Household food insecurity and hunger among households in Sidama district, southern Ethiopia. Public Health Nutr. 2012, 15, 1276-1283. [CrossRef]

45. Eaton, L.A.; Cain, D.N.; Pitpitan, E.V.; Carey, K.B.; Carey, M.P.; Mehlomakulu, V.; Simbayi, L.C.; Mwaba, K.; Kalichman, S.C. Exploring the relationships among food insecurity, alcohol use, and sexual risk taking among men and women living in South African town-ships. J. Prim. Prev. 2014, 35, 255-265. [CrossRef]

46. Kalichman, S.C.; Watt, M.; Sikkema, K.; Skinner, N.; Pieterse, D. Food insufficiency, substance use, and sexual risks for HIV/AIDS in informal drinking establishments, Cape Town, South Africa. J. Urban Health 2012, 89, 939-951. [CrossRef] 
47. Yerges, A.L.; Stevens, P.E.; Mkandawire-Valhmu, L.; Bauer, W.; Ng'ombe Mwenyekonde, T.; Weinhardt, L.S.; Galvao, L.W. Women's narratives of living in polygamous marriages: Rural Malawian experience distilled and preserved in poetic constructions. Health Care Women Int. 2017, 38, 873-891. [CrossRef]

48. Mkandawire-Valhmu, L.; Bauer, W.S.; Stevens, P.E.; Galvao, L.W.; Grande, K.M.; Yerges, A.; Emer, L.; Mwenyekonde, T.; Weinhardt, L. Rural Malawian Women's Resistance to Systematic Oppression, Violence, and Abuse by Their Husbands. J. Interpers. Violence 2016, 35, 268-293. [CrossRef]

49. Aberman, N.-L.; Roopnaraine, T. To sell or consume? Gendered household decision-making on crop production, consumption, and sale in Malawi. Food Secur. 2020, 12, 433-447. [CrossRef]

50. Erlingsen, C.; Brysiewicz, P. A hands-on guide to doing content analysis. Afr. J. Emerg. Med. 2017, 7, 93-99. [CrossRef] [PubMed]

51. Foltz, P.W. Latent semantic analysis for text-based research. Behav. Res. Methods Instrum. Comput. 1996, 2, 197-202. [CrossRef]

52. UN. Universal Declaration of Human Rights; United Nations: New York, NY, USA, 1948.

53. UN. UN Convention on Economic Social and Cultural Rights; UN: New York, NY, USA, 1976.

54. UN. Convention of the Elimination of all Forms of Discrimination against Women; United Nations: New York, NY, USA, 1981.

55. FAO. World Declaration and Plan of Action for Nutrition; FAO: Rome, Italy, 1992.

56. UN. Beijing Declaration and Platform for Action; UN: New York, NY, USA, 1995.

57. FAO. Rome Declaration on World Food Security; FAO: Rome, Italy, 1996.

58. AUC. Protocol to the African Charter on Human and Peoples' Rights on the Rights of Women in Africa; AUC: Addis Ababa, Ethiopia, 2003.

59. FAO. Voluntary Guidelines on the Right to Food; FAO: Rome, Italy, 2005.

60. FAO. Declaration on the World Food Summit; FAO: Rome, Italy, 2009.

61. Committee on World Food Security. Voluntary Guidelines on the Responsible Governance of Land Tenure of Land, Fisheries and Forests in the Context of National Food Security; CFS: Rome, Italy, 2012.

62. AUC. Malabo Declaration of Accelerated Agricultural Growth and Transformation for Shared Prosperity and Improved Livelihoods; African Union Commission: Addis Ababa, Ethiopia, 2014.

63. FAO. Rome Declaration on Nutrition; FAO: Rome, Italy, 2014.

64. Committee on World Food Security. Principles for Responsible Investment in Agriculture and Food Systems; CFS: Rome, Italy, 2014.

65. AUC. Africa Agenda 2063: First Ten-Year Implementation Plan 2013-2023; AUC: Addis Ababa, Ethiopia, 2015.

66. AUC. Africa Regional Nutrition Strategy 2015-2025; AUC: Addis Ababa, Ethiopia, 2015.

67. AUC. Malabo Implementation Strategy and Roadmap to Achieve the 2025 Vision on CAADP; AUC: Addis Ababa, Ethiopia, 2015.

68. UNGA. Transforming our World: The 2030 Agenda for Sustainable Development. General Assembley 70 Session; UNGA: New York, NY, USA, 2015.

69. Gondwe, T.A.; Tegbaru, A.E.; Oladeji, M.; Khonje, J.; Manda, H.; Gaya, H. Correlates and consequences of women's participation in the cowpea value chain in eastern Zambia. Agric. Econ. Res. Policy Pract. S. Afr. 2017, 56. [CrossRef]

70. Owusu, V.; Donkor, E.; Owusu-Sekyere, E. Accounting for the Gender Technology Gap amongst Small-holder Rice Farmers in Northern Ghana. J. Agric. Econ. 2017, 69, 439-457. [CrossRef]

71. Kristjanson, P.; Bryan, E.; Bernier, Q.; Twyman, J.; Meinzen-Dick, R.; Kieran, C.; Ringler, C.; Jost, C.; Doss, C. Addressing gender in agricultural research for development in the face of a changing climate: Where are we and where should we be going? Int. J. Agric. Sustain. 2017, 15, 482-500. [CrossRef]

72. Doss, C.R. Women and agricultural productivity: Reframing the Issues. Dev. Policy Rev. 2018, 36, 35-50. [CrossRef]

73. Johnston, D.S.; Stevano, S.J.; Malapit, H.J.; Hull, E.; Kadiyala, S. Review: Time Use as an Explanation for the Agri-Nutrition Disconnect: Evidence from Rural Areas in Low and Middle-Income Countries. Food Policy 2018, 76, 8-18. [CrossRef]

74. Rao, N.; Gazdar, H.; Chanchani, D.; Ibrahim, M. Women's agricultural work and nutrition in South Asia: From pathways to a cross-disciplinary, grounded analytical framework. Food Policy 2019, 82, 50-62. [CrossRef]

75. Mkandawire, E.; Hendriks, S.L. A qualitative analysis of men's involvement in maternal and child health as a policy intervention in rural Central Malawi. BMC Pregnancy Childbirth 2018, 18. [CrossRef] [PubMed]

76. Adzawla, W.; Azumah, S.B.; Anani, P.Y.; Donkoh, S.A. Gender perspectives of climate change adaptation in two selected districts of Ghana. Heliyon 2019, 5. [CrossRef] [PubMed]

77. Jones, N.; Holmes, R. Why is Social Protection Genderblind? The Politics of Gender and Social Protection. IDS Bull. $2012,42,45-52$.

78. Lemke, S.; Delormier, T. Indegenous Peoples' food systems, nutrition and gender: Conceptual and methodological considerations. Matern. Child Nutr. 2017, 13. [CrossRef]

79. UN. Paris Agreement; UN: New York, NY, USA, 2015.

80. Towards gender transformative agriculture and food systems: Where next. In Tansforming Gender and Food Security in the Global South; Njuki, J.; Kaler, A.; Parkins, J.R. (Eds.) Routledge: London, UK; New York, NY, USA, 2016; pp. $283-289$. 